\title{
Revisiting risks associated with mortality following initial transtibial or transfemoral amputation
}

\author{
Barbara E. Bates, MD, MBA; ${ }^{*}$ Dawei Xie, PhD; ${ }^{2}$ Jibby E. Kurichi, MPH; $^{2}$ Diane Cowper Ripley, PhD; ${ }^{3}$ Pui L. \\ Kwong, MPH; ${ }^{2}$ Margaret G. Stineman, $\mathrm{MD}^{2,4}$ \\ ${ }^{1}$ Albany Stratton Department of Veterans Affairs (VA) Medical Center, Albany, NY; and Department of Physical Medi- \\ cine and Rehabilitation, Albany Medical College, Albany, NY; ${ }^{2}$ Center for Clinical Epidemiology and Biostatistics, \\ University of Pennsylvania, Philadelphia, PA; ${ }^{3}$ North Florida/South Georgia Veterans Hospital System, Gainesville, \\ FL; and Department of Health Outcomes and Policy, College of Medicine, University of Florida, Gainesville, FL; \\ ${ }^{4}$ Department of Physical Medicine and Rehabilitation, University of Pennsylvania, Philadelphia, PA
}

\begin{abstract}
This study's objective was to determine how treatment-, environmental-, and facility-level characteristics contribute to postdischarge mortality prediction. The study included 4,153 Veterans who underwent lower-limb amputation in Department of Veterans Affairs facilities during fiscal years 2003 and 2004. Veterans were followed 1 yr postamputation. A Cox regression identified characteristics associated with mortality risk after hospital discharge following amputation. Older age, higher amputation level, and more comorbidities increased mortality likelihood. Patients who had inpatient procedures for pulmonary and renal problems had higher hazards of postdischarge death than those who did not (hazard ratio $[\mathrm{HR}]=2.10,95 \%$ confidence interval $[\mathrm{CI}]=1.16-3.77$, and $\mathrm{HR}=2.22$, 95\% CI $=1.80-2.74$, respectively). Patients who had central nervous system procedures had higher hazards of death early postdischarge $(\mathrm{HR}=2.23$, 95\% CI = 1.60-3.11) at $0 \mathrm{~d}$, but this association became insignificant by $180 \mathrm{~d}$. Patients in a surgical intensive care unit (ICU), medical ICU, or medical bed section at the time of discharge were more likely to die than patients on a surgical bed section. Patients hospitalized in the Midwest were less likely to die early after discharge than patients in the Mountain Pacific region, but this regional effect became insignificant by $90 \mathrm{~d}$. Adding treatment-, environmental-, and facility-level characteristics contributed additional information to a mortality risk model.
\end{abstract}

Key words: administrative data, amputation, comorbidity, elderly, integrated, lower limb, mortality, outcome assessment, rehabilitation, Veteran.

\section{INTRODUCTION}

Lower-limb amputation (LLA) resulting from chronic disease such as diabetes carries a high mortality rate, particularly for those with concomitant medical conditions and those who undergo a higher level amputation [1-6]. Tseng et al., using retrospective data, recently showed that, while initial major LLA rates declined in the Department of Veterans Affairs (VA) by 36 percent between fiscal years (FYs) 2000 and 2004, the total number of Veterans undergoing a major LLA increased from 1,008 to 1,247 during the same time frame [7]. Others have found similar trends in the general U.S. population [8-9]. To better understand the medical conditions and other important covariates associated with mortality among Veterans who undergo transtibial or transfemoral amputation in

\footnotetext{
Abbreviations: $\mathrm{AHA}=$ American Hospital Association, $\mathrm{CI}=$ confidence interval, FY = fiscal year, $\mathrm{HR}=$ hazard ratio, $\mathrm{ICU}=$ intensive care unit, LLA = lower-limb amputation, NF/SG VHS = North Florida/South Georgia Veterans Health System, $\mathrm{VA}=$ Department of Veterans Affairs, VAMC = VA medical center.

*Address all correspondence to Barbara E. Bates, MD, MBA; VAMC (117), 113 Holland Ave, Albany, NY 12208; 518-626-5817. Email: Barbara.bates@va.gov http://dx.doi.org/10.1682/JRRD.2012.02.0030
} 
VA medical centers (VAMCs), we have expanded on work previously presented, adding inpatient procedures, geographic region, travel time to nearest hospital, and hospital characteristics to our original model of mortality risk following LLA [1].

\section{METHODS}

\section{Sources of Data}

Data used for this study were acquired from eight Veterans Health Administration administrative databases. These databases captured various aspects of the Veterans' healthcare utilization. The data sources and how the data were used have been described previously [10-17]. Travel time to the nearest hospital was calculated using the 2007 American Hospital Association (AHA) Annual Survey Database for hospital location and the Veterans' ZIP code of residence from the Medical SAS Datasets. With the latitude and longitude of these two points, ArcGIS 10 software (Esri; Redlands, California) was used to determine the travel time, adjusting for road type and population density. Data on hospitals can be purchased from the AHA Web site: http://www.ahadata.com/ahadata/ html/AHASurvey.html.

\section{Study Population}

Study subjects who had LLAs during FYs 2003 and 2004 (referred to as waves 1 and 2) were included. Inclusion criteria were being discharged from a VAMC between October 1, 2002, and September 30, 2004, and LLA as indicated with one of the following surgical procedure codes in the medical record: 84.10, 84.13-84.19, and 84.91 [4]. If a patient had amputation of the toes only or evidence of a previous LLA within the year prior to the "index surgical stay," or the hospitalization from admission to discharge of the new amputation of interest, the patient was excluded from the study. To obtain the entire index surgical stay, medical records with admission or discharge dates within $24 \mathrm{~h}$ of the LLA record were merged together. Data for this study include information up to the $1 \mathrm{yr}$ anniversary of the LLA surgical date.

We began with a total of 4,727 subjects from waves 1 and 2. Since the focus of the study was to determine factors associated with mortality after being discharged from the index surgical stay, the following groups of patients were excluded: 364 patients who died during the index surgical stay, 17 whose index surgical stay was more than $365 \mathrm{~d}$ after the surgical amputation and thus had no mortality follow-up data available, and 131 who were discharged to another hospital because we could not calculate time travel from the home ZIP code to the nearest hospital ZIP code for these patients.

We also excluded 62 patients because they were missing at least one of the predictors:

- 49 patients with a V57 code, indicating that they received inpatient rehabilitation, but without evidence of a Functional Status and Outcomes Database record to designate which type of inpatient rehabilitation was received during the index surgical stay.

- 1 patient missing living location before hospitalization information.

- 12 patients missing travel time from their home ZIP code to the ZIP code of the nearest hospital, either a VA facility or community hospital.

Subsequently, 4,153 unique veterans with an LLA were included in the analyses.

\section{Patient-, Treatment-, Environmental-, and Facility- Level Characteristic Definitions}

Patient-level characteristics were selected based on the Post Amputation Quality-of-Life framework [16]. Domains within the framework incorporated in this study included demographics, amputation level, contributing amputation etiologies, comorbidities, and medical acuity. The independent variables are based on the index surgical stay discharge date unless otherwise noted.

Demographics comprised age (continuous), sex, source of hospital admission (home, hospital, or extended care), and marital status (married or not married). Level of LLA differentiated between unilateral and bilateral as well as transtibial and transfemoral. Because there were only a few cases, those study subjects who underwent both a transtibial and a transfemoral amputation were combined with the bilateral transfemoral group.

Etiologies and comorbidities were identified using the International Classification of Diseases-Ninth Revision-Clinical Modification codes from the outpatient files 3 mo prior to the index surgical stay admission date and from the inpatient files up to the surgical date. Our group classified 12 amputation etiologies, 10 of which were included in the study [1]. The amputation etiologies of lower-limb cancer and congenital deformity were not included because of low prevalence. The 2003 version of the Elixhauser comorbidity measure was used in the 
analyses. This version incorporates 31 conditions and differentiates between hypertension with and without complications. Obesity was not included because no study subject had evidence of this condition. Peripheral vascular disease and diabetes were classified as amputation etiologies and thus were not considered comorbidities.

Treatment-level variables incorporated in this study have been described previously [16]. Additional factors included in the study were the average number of bed sections patients were cared for on during the index surgical stay, bed section location at the time of hospital discharge, average length of stay of the entire hospitalization (in days), average length of stay from the hospital admission to the amputation date (in days), average length of stay from the amputation to the hospital discharge date (in days), and type of inpatient rehabilitation received (no evidence of inpatient rehabilitation, consultation rehabilitation, or specialized rehabilitation).

Environmental-level variables included discharge location from the index surgical stay (home or extended care) and travel time. Travel time was measured as the time in minutes required for a patient to travel from the patient's home ZIP code to the ZIP code of the nearest hospital, either VA facility or community hospital. A travel time of 0 min would indicate that a hospital was in the same ZIP code as the patient's residence. Longer travel times would indicate that patients live in a ZIP code that is farther away from the ZIP code of the nearest hospital.

We included three facility-level characteristics in this study. Geographic regions were categorized as Northeast, Southeast, Midwest, South Central, or Pacific Mountain. Hospital bed size was added as a categorical variable $(\leq 126,127-244,245-362$, or $>362)$. Presence of a CARF (Commission on Accreditation of Rehabilitation Facilities) accredited program at the VAMC where the Veteran underwent the LLA was also included.

Because 2 yr of data were used in the study, a year variable was included.

\section{Outcome}

Time to death following the index surgical stay discharge date was the primary outcome of this study. Mortality was obtained through evidence of a death date found in the Beneficiary Identification Records Locator Subsystem death file.

\section{Statistical Analyses}

Baseline patient-, treatment-, environmental-, and facility-level characteristics were contrasted between study subjects who did and did not die within the study period time frame through chi-square tests or Student $t$-tests.

A Cox proportional hazards model [18], which is a time to event analysis, was used to determine the hazard ratio (HR) and 95 percent confidence interval (CI) of Veterans dying after being discharged from the surgical amputation hospitalization.

Each patient-, treatment-, environmental-, and facility-level variable was entered by itself to predict time to mortality. If the $p$-value was $<0.05$, then the variable was included in the multivariate model. Also included in the multivariate model were clinically important factors such as age, sex, marital status, amputation level, and source of hospital admission, regardless of whether the $p$-value was $<0.05$ in the unadjusted analysis. The travel time variable was entered in the model as a continuous variable. We also tested time travel as a quadratic term to model nonlinearity. Because the quadratic term was not significant in the unadjusted model, we retained only the linear form. The backward selection technique was used to eliminate variables by one to reach the final main effect model where $p$-values for all variables are $<0.05$.

To see if the HRs stayed the same over time, the Cox regression model's proportional hazards assumption was tested. The interaction between each factor in the final main effect model and time to death or the end of the follow-up period was added to the final main effect model. We added all interactions with $p<0.05$ in the previous step before a final backward selection procedure was conducted to obtain the final model with main effects and interactions. In the cases where the variables violated the proportional hazards assumption, HRs and 95 percent CIs at $0,90,180,270$, and $365 \mathrm{~d}$ after discharge from the amputation hospitalization were calculated. For the variables that did not violate the proportional hazards assumption, the constant HRs and 95 percent CIs were reported. All models took into account the correlation among patients from the same facility. PROC TPHREG in SAS 9.1 (SAS; Cary, North Carolina) was used for all time-to-event analyses. The $p$-values were two-sided, with statistical significance at $p<0.05$ in the final models. 


\section{RESULTS}

A total of 720 (17.34\%) Veterans with LLA died during the $1 \mathrm{yr}$ after being discharged from the index surgical stay, while 3,433 (82.66\%) did not. The average age was $66.58 \mathrm{yr}$ (standard deviation $=11.20$ ), and 41.63 percent had unilateral transtibial amputations. There were 195 (4.70\%) cases with 0 min travel time, 363 (8.74\%) with $1 \mathrm{~min}$ travel time, 2,617 (63.01\%) with 2 to $10 \mathrm{~min}$ travel time, and 978 (23.55\%) who had travel times $\geq 11$ min from their home ZIP code to the ZIP code of the nearest hospital. Table 1 includes the unadjusted results comparing the baseline characteristics of patients who did and did not die after being discharged from the index surgical stay.

The variables that did not violate the proportional hazards assumption after adjusting for patient-, treatment-, environmental-, and facility-level characteristics are found in Table 2. Younger Veterans were less likely to die after being discharged from the index surgical stay. Patients who were admitted to the hospital from home ( $\mathrm{HR}=0.74,95 \% \mathrm{CI}=0.58-0.94)$ or transferred from another hospital $(\mathrm{HR}=0.69,95 \% \mathrm{CI}=0.52-0.90)$ were less likely to die than patients admitted to the hospital from extended care. Those with an amputation etiology of problems with peripheral circulation (HR $=1.41$, 95\% $\mathrm{CI}=1.07-1.85)$ or systemic sepsis $(\mathrm{HR}=1.31,95 \% \mathrm{CI}=$ 1.04-1.64) were more likely to die after being discharged than those without these contributing amputation etiologies. Veterans with chronic osteomyelitis $(\mathrm{HR}=0.67$, $95 \%$ CI $=0.47-0.94$ ) were less likely to die. Patients with evidence of the comorbid conditions of chronic pulmonary disease $(\mathrm{HR}=1.38,95 \% \mathrm{CI}=1.16-1.64)$, congestive heart failure ( $\mathrm{HR}=1.34,95 \% \mathrm{CI}=1.14-1.58)$, fluid and electrolyte disorders ( $\mathrm{HR}=1.25,95 \% \mathrm{CI}=1.05$ 1.48), metastatic cancer ( $\mathrm{HR}=3.48,95 \% \mathrm{CI}=2.27-$ 5.33), pulmonary circulation disease $(\mathrm{HR}=2.21,95 \% \mathrm{CI}=$ 1.14-4.30), solid tumor without metastasis $(\mathrm{HR}=1.77$, $95 \% \mathrm{CI}=1.42-2.22)$, or weight loss ( $\mathrm{HR}=1.50,95 \% \mathrm{CI}=$ 1.14-1.98) were more likely to die after being discharged from the index surgical stay. Veterans who underwent procedures for active pulmonary pathology $(\mathrm{HR}=2.10$, $95 \% \mathrm{CI}=1.16-3.77)$ or severe renal disease $(\mathrm{HR}=2.22$, $95 \%$ CI $=1.80-2.74$ ) were more likely to die. Compared with being discharged from a surgical bed section, patients who were discharged from a surgical intensive care unit (ICU) $(\mathrm{HR}=1.94,95 \% \mathrm{CI}=1.10-3.42)$, medical $(\mathrm{HR}=1.86,95 \% \mathrm{CI}=1.51-2.28)$, or medical ICU
( $\mathrm{HR}=4.55,95 \% \mathrm{CI}=2.62-7.90)$ bed sections were more likely to die. Compared with patients who received inpatient specialized rehabilitation services, patients who received inpatient consultative rehabilitation services $(\mathrm{HR}=1.65,95 \% \mathrm{CI}=1.11-2.45)$ were significantly more likely to die, while those with no evidence of inpatient rehabilitation were marginally more likely to die $(\mathrm{HR}=1.66,95 \% \mathrm{CI}=0.97-2.86, p=0.07)$. Patients whose travel time from their home ZIP code to the closest hospital ZIP code was shorter were more likely to die than patients who had longer travel times from their home ZIP code to the closest hospital ZIP code (HR = 0.99, 95\% CI $=0.98-0.99$ ).

Several variables violated the proportional hazards assumption, indicating that their HRs of dying after discharge from the index surgical stay did not remain constant over time (Table 3). Compared with patients who underwent a unilateral transtibial amputation, patients who had a unilateral transfemoral amputation or bilateral transfemoral amputation were more likely to die up to $90 \mathrm{~d}$ after discharge from the index surgical stay. Both HRs decreased over time. Patients who had procedures suggestive of acute central nervous system pathology were more likely to die through $90 \mathrm{~d}$, but those HRs decreased over time as well. The hazards of dying for those living in the Northeast region were higher only at the time of discharge from the index surgical stay compared with the Mountain Pacific region, while patients living in the Midwest were less likely to die at discharge. There was no difference in the hazards of dying between patients in waves 1 and 2 at the time of discharge. However, after $90 \mathrm{~d}$, patients in wave 2 were less likely to die.

\section{DISCUSSION}

Expanding on our original study, we added a number of variables to our model, including structural factors, treatment processes (procedures that occurred during the index surgical stay), and distance to nearest hospital. We also added an additional 12 mo of data and established a more sophisticated analytic strategy than originally used.

\section{Patient-Level Characteristics}

In general and consistent with other studies [1,34,19-20], older patients, patients with bilateral amputations, and patients with greater comorbidities and evidence of greater acuity during the index surgical stay 
Table 1.

Unadjusted baseline characteristics comparing patients who did and did not die after being discharged from index surgical stay. Data presented as $n$ (\%) unless otherwise indicated.

\begin{tabular}{|c|c|c|c|}
\hline Characteristic & $\begin{array}{l}\text { Death after Being Discharged } \\
\text { from Index Surgical Stay } \\
\qquad(n=720)\end{array}$ & $\begin{array}{l}\text { Alive after Being Discharged } \\
\text { from Index Surgical Stay } \\
\qquad(n=3,433)\end{array}$ & $p$-Value \\
\hline Demographic Contents & & & $<0.001$ \\
\hline Age, yr (mean \pm SD) & $71.33 \pm 10.57$ & $65.59 \pm 11.05$ & \\
\hline Sex & & & 0.80 \\
\hline Male & 714 (17.35) & $3,401(82.65)$ & \\
\hline Female & $6(15.79)$ & $32(84.21)$ & \\
\hline Marital Status & & & 0.01 \\
\hline Married & $356(19.01)$ & 1,517 (80.99) & \\
\hline Not Married & $364(15.96)$ & $1,916(84.04)$ & \\
\hline Living Location Before Hospitalization & & & $<0.001$ \\
\hline Home & $579(16.11)$ & 3,015 (83.89) & \\
\hline Hospital & $15(16.48)$ & $76(83.52)$ & \\
\hline Extended Care & $126(26.92)$ & $342(73.08)$ & \\
\hline Level of Amputation & & & $<0.001$ \\
\hline Unilateral Transtibial & $212(12.26)$ & $1,517(87.74)$ & \\
\hline Unilateral Transfemoral & 194 (19.40) & $806(80.60)$ & \\
\hline Bilateral Transtibial & 15 (16.85) & $74(83.15)$ & \\
\hline Bilateral Transfemoral & $299(22.40)$ & $1,036(77.60)$ & \\
\hline \multicolumn{4}{|l|}{ Amputation Etiology } \\
\hline Chronic Osteomyelitis & & & $<0.01$ \\
\hline Yes & $35(10.74)$ & $291(89.26)$ & \\
\hline No & $685(17.90)$ & $3,142(82.10)$ & \\
\hline Device Infection & & & 0.05 \\
\hline Yes & $67(14.14)$ & 407 (85.86) & \\
\hline No & $653(17.75)$ & $3,026(82.25)$ & \\
\hline Diabetes Mellitus Type 1 & & & 0.32 \\
\hline Yes & $104(15.98)$ & $547(84.02)$ & \\
\hline No & $616(17.59)$ & $2,886(82.41)$ & \\
\hline Diabetes Mellitus Type 2 & & & 0.71 \\
\hline Yes & 485 (17.19) & 2,337 (82.81) & \\
\hline No & $235(17.66)$ & $1,096(82.34)$ & \\
\hline Local Significant Infection & & & $<0.01$ \\
\hline Yes & $583(18.32)$ & $2,599(81.68)$ & \\
\hline No & $137(14.11)$ & $834(85.89)$ & \\
\hline \multicolumn{4}{|l|}{ Peripheral Vascular Disease } \\
\hline Yes & $659(18.30)$ & $2,942(81.70)$ & $<0.001$ \\
\hline No & $61(11.05)$ & $491(88.95)$ & \\
\hline Previous Amputation Complication & & & 0.07 \\
\hline Yes & $51(13.90)$ & $316(86.10)$ & \\
\hline No & $669(17.67)$ & 3,117 (82.33) & \\
\hline Skin Breakdown & & & 0.89 \\
\hline Yes & $473(17.40)$ & $2,246(82.60)$ & \\
\hline No & $247(17.22)$ & $1,187(82.78)$ & \\
\hline Systemic Sepsis & & & $<0.01$ \\
\hline Yes & $93(23.91)$ & $296(76.09)$ & \\
\hline No & $627(16.66)$ & 3,137 (83.34) & \\
\hline
\end{tabular}


Table 1. (cont)

Unadjusted baseline characteristics comparing patients who did and did not die after being discharged from index surgical stay. Data presented as $n$ (\%) unless otherwise indicated.

\begin{tabular}{|c|c|c|c|}
\hline Characteristic & $\begin{array}{l}\text { Death after Being Discharged } \\
\text { from Index Surgical Stay } \\
\qquad(n=720)\end{array}$ & $\begin{array}{l}\text { Alive after Being Discharged } \\
\text { from Index Surgical Stay } \\
\qquad(n=3,433)\end{array}$ & $p$-Value \\
\hline Trauma & & & 0.04 \\
\hline Yes & 87 (14.43) & $516(85.57)$ & \\
\hline No & $633(17.83)$ & 2,917 (82.17) & \\
\hline \multicolumn{4}{|l|}{ Elixhauser Comorbidities } \\
\hline \multicolumn{4}{|l|}{ AIDS } \\
\hline Yes & $3(13.04)$ & $20(86.96)$ & 0.59 \\
\hline No & 717 (17.36) & 3,413 (82.64) & \\
\hline Alcohol Abuse & & & $<0.01$ \\
\hline Yes & $24(10.13)$ & $213(89.87)$ & \\
\hline No & 696 (17.77) & $3,220(82.23)$ & \\
\hline Arrhythmia & & & $<0.001$ \\
\hline Yes & $163(23.83)$ & $521(76.17)$ & \\
\hline No & $557(16.06)$ & 2,912 (83.94) & \\
\hline Chronic Blood Loss Anemia & & & 0.02 \\
\hline Yes & $20(28.17)$ & $51(71.83)$ & \\
\hline No & 700 (17.15) & 3,382 (82.85) & \\
\hline Chronic Pulmonary Disease & & & $<0.001$ \\
\hline Yes & $195(23.96)$ & $619(76.04)$ & \\
\hline No & 525 (15.72) & 2,814 (84.28) & \\
\hline \multicolumn{4}{|l|}{ Coagulopathy } \\
\hline Yes & $41(22.28)$ & $143(77.72)$ & 0.07 \\
\hline No & 679 (17.11) & 3,290 (82.89) & \\
\hline \multicolumn{4}{|l|}{ Congestive Heart Failure } \\
\hline Yes & $231(24.52)$ & $711(75.48)$ & $<0.001$ \\
\hline No & 489 (15.23) & 2,722 (84.77) & \\
\hline Deficiency Anemia & & & $<0.01$ \\
\hline Yes & $193(20.34)$ & 756 (79.66) & \\
\hline No & $527(16.45)$ & 2,677 (83.55) & \\
\hline Depression & & & 0.97 \\
\hline Yes & $71(17.27)$ & $340(82.73)$ & \\
\hline No & $649(17.34)$ & 3,093 (82.66) & \\
\hline Drug Abuse & & & 0.02 \\
\hline Yes & $9(8.82)$ & 93 (91.18) & \\
\hline No & $711(17.55)$ & $3,340(82.45)$ & \\
\hline Fluid and Electrolyte Disorder & & & $<0.001$ \\
\hline Yes & $196(22.69)$ & $668(77.31)$ & \\
\hline No & $524(15.93)$ & $2,765(84.07)$ & \\
\hline Hypertension & & & 0.02 \\
\hline Yes & $424(16.25)$ & 2,186 (83.75) & \\
\hline No & $296(19.18)$ & $1,247(80.82)$ & \\
\hline Hypertension with Complication & & & 0.36 \\
\hline Yes & $5(25.00)$ & $15(75.00)$ & \\
\hline No & $715(17.30)$ & $3,418(82.70)$ & \\
\hline Hypothyroidism & & & 0.01 \\
\hline Yes & 39 (24.68) & $119(75.32)$ & \\
\hline No & $681(17.05)$ & 3,314 (82.95) & \\
\hline
\end{tabular}


Table 1. (cont)

Unadjusted baseline characteristics comparing patients who did and did not die after being discharged from index surgical stay. Data presented as $n$ (\%) unless otherwise indicated.

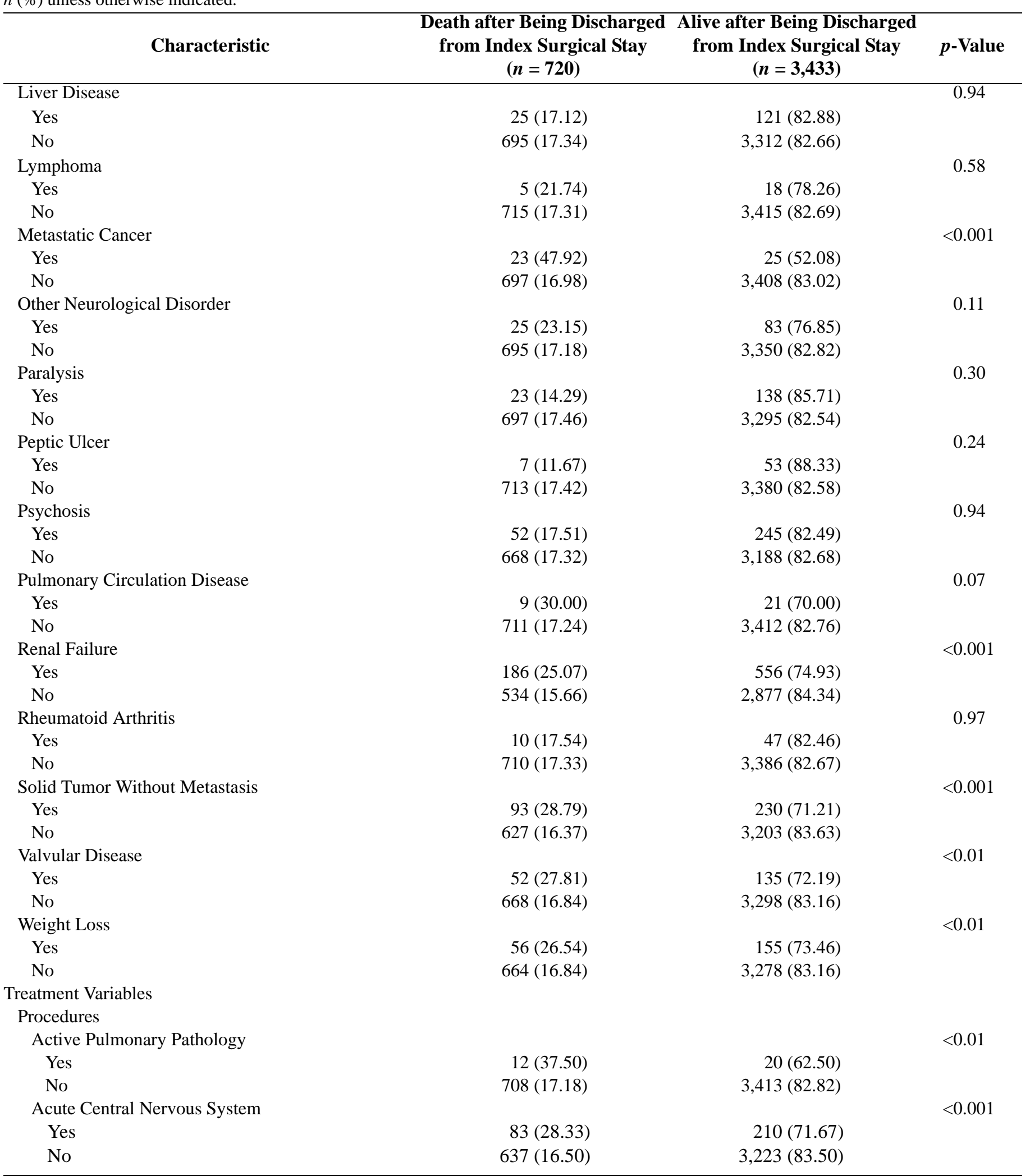


Table 1. (cont)

Unadjusted baseline characteristics comparing patients who did and did not die after being discharged from index surgical stay. Data presented as $n(\%)$ unless otherwise indicated.

\begin{tabular}{|c|c|c|c|}
\hline Characteristic & $\begin{array}{l}\text { Death after Being Discharged } \\
\text { from Index Surgical Stay } \\
\qquad(n=720)\end{array}$ & $\begin{array}{l}\text { Alive after Being Discharged } \\
\text { from Index Surgical Stay } \\
\qquad(n=3,433)\end{array}$ & $p$-Value \\
\hline Mental Health/Substance Abuse & & & 0.85 \\
\hline Yes & $9(16.36)$ & 46 (83.64) & \\
\hline No & $711(17.35)$ & 3,387 (82.65) & \\
\hline Ongoing Active Cardiac Pathology & & & 0.03 \\
\hline Yes & 95 (20.93) & 359 (79.07) & \\
\hline No & $625(16.90)$ & 3,074 (83.10) & \\
\hline Ongoing Wound Problem & & & 0.32 \\
\hline Yes & $36(15.00)$ & $204(85.00)$ & \\
\hline No & $684(17.48)$ & $3,229(82.52)$ & \\
\hline Serious Nutritional Compromise & & & $<0.001$ \\
\hline Yes & $48(36.36)$ & $84(63.64)$ & \\
\hline No & $672(16.71)$ & 3,349 (83.29) & \\
\hline Severe Renal Disease & & & $<0.001$ \\
\hline Yes & $112(32.56)$ & $232(67.44)$ & \\
\hline No & $608(15.96)$ & $3,201(84.04)$ & \\
\hline $\begin{array}{l}\text { No. of Bed Sections Treated on During Index } \\
\text { Surgical Stay, mean } \pm \text { SD }\end{array}$ & $2.52 \pm 1.89$ & $2.27 \pm 1.67$ & $<0.01$ \\
\hline Bed Section at Time of Discharge & & & $<0.001$ \\
\hline Surgical & 198 (13.78) & $1,239(86.22)$ & \\
\hline Intensive Care Unit (surgical) & $13(34.21)$ & 25 (65.79) & \\
\hline Medical & $213(29.34)$ & $513(70.66)$ & \\
\hline Intensive Care Unit (medical) & $14(53.85)$ & $12(46.15)$ & \\
\hline Psychiatric & $1(20.00)$ & $4(80.00)$ & \\
\hline High Intensity Rehabilitation & $23(6.08)$ & $355(93.92)$ & \\
\hline Spinal Cord Injury & $7(12.28)$ & $50(87.72)$ & \\
\hline Extended Care & $55(17.80)$ & $254(82.20)$ & \\
\hline Peripheral Vascular Surgery & $196(16.65)$ & $981(83.35)$ & \\
\hline Length of Stay, d (mean \pm SD) & $26.34 \pm 26.48$ & $25.08 \pm 28.54$ & 0.25 \\
\hline Admission to Surgery, $\mathrm{d}$ (mean $\pm \mathrm{SD}$ ) & $9.17 \pm 14.49$ & $7.97 \pm 13.13$ & 0.04 \\
\hline Surgery to Discharge, d (mean \pm SD) & $17.32 \pm 19.62$ & $17.33 \pm 22.55$ & 0.99 \\
\hline Type of Inpatient Rehabilitation & & & $<0.001$ \\
\hline No Evidence of Inpatient Rehabilitation & $271(22.75)$ & $920(77.25)$ & \\
\hline Consultative Rehabilitation & $403(17.03)$ & 1,964 (82.97) & \\
\hline Specialized Rehabilitation & $46(7.73)$ & 549 (92.27) & \\
\hline \multicolumn{4}{|l|}{ Environmental Characteristics } \\
\hline Discharge Location & & & $<0.01$ \\
\hline Home & $396(15.70)$ & $2,126(84.30)$ & \\
\hline Extended Care & $324(19.87)$ & $1,307(80.13)$ & \\
\hline $\begin{array}{l}\text { Travel Time from Home ZIP Code to ZIP Code of } \\
\text { Closest Hospital, min (mean } \pm \text { SD) }\end{array}$ & $7.14 \pm 6.51$ & $7.77 \pm 7.65$ & 0.02 \\
\hline \multicolumn{4}{|l|}{ Facility Characteristics } \\
\hline Regions & & & $<0.01$ \\
\hline Northeast & $115(20.21)$ & 454 (79.79) & \\
\hline Southeast & $251(19.97)$ & $1,006(80.03)$ & \\
\hline Midwest & $119(15.26)$ & $661(84.74)$ & \\
\hline South Central & 139 (15.27) & 771 (84.73) & \\
\hline
\end{tabular}


Table 1. (cont)

Unadjusted baseline characteristics comparing patients who did and did not die after being discharged from index surgical stay. Data presented as $n$ (\%) unless otherwise indicated.

\begin{tabular}{|c|c|c|c|}
\hline Characteristic & $\begin{array}{l}\text { Death after Being Discharged } \\
\text { from Index Surgical Stay } \\
(n=720)\end{array}$ & $\begin{array}{l}\text { Alive after Being Discharged } \\
\text { from Index Surgical Stay } \\
\qquad(n=3,433)\end{array}$ & $p$-Value \\
\hline Mountain Pacific & $96(15.07)$ & $541(84.93)$ & \\
\hline Total Bed Size & & & 0.01 \\
\hline$\leq 126$ & 206 (17.99) & $939(82.01)$ & \\
\hline $127-244$ & $184(14.84)$ & $1,056(85.16)$ & \\
\hline $245-362$ & $268(18.03)$ & 1,218 (81.97) & \\
\hline$>362$ & 62 (21.99) & $220(78.01)$ & \\
\hline CARF Accreditation & & & 0.39 \\
\hline Yes & 345 (16.83) & 1,705 (83.17) & \\
\hline No & 375 (17.83) & $1,728(82.17)$ & \\
\hline Wave & & & $<0.001$ \\
\hline Year 1 & $433(20.85)$ & 1,644 (79.15) & \\
\hline Year 2 & 287 (13.82) & 1,789 (86.18) & \\
\hline
\end{tabular}

were more likely to die after being discharged. Patients who were married also had poorer survival in the unadjusted model than those who were not. A similar finding was seen among those who were admitted from an extended care facility. Comorbid conditions including cardiac arrhythmias (unadjusted association only), chronic pulmonary disease, congestive heart failure, fluid and electrolyte disorders, metastatic cancer, renal failure (unadjusted association only), solid tumor without metastasis, and weight loss were all associated with higher mortality within $1 \mathrm{yr}$ of discharge from the index surgical stay. Remes et al. found that the presence of cardiovascular disease predicted both early and late postoperative mortality following major LLA but that lung disease did not [6]. Others have found higher mortality rates in persons with even moderate renal insufficiency $[4,20]$. Patients with significant comorbidities such as heart, lung, and/or renal disease are likely to be frail with minimal functional reserve. The added burden brought on by a new amputation further reduces their activity level, leaving them at high risk for complications associated with immobility.

Veterans admitted from home or transferred from another hospital were less likely to die within $1 \mathrm{yr}$ of discharge than those admitted from extended care. Again, Veterans residing in extended care facilities at the time of the need for an LLA are likely to have diminished functional capacity, be in poorer health overall, and lack the reserves to fully recover function following the amputation.

\section{Treatment-Level Characteristics}

Higher medical acuity as evidenced by being treated on a greater number of bed sections; being treated in a medical or surgical ICU; and requiring medical procedures such as for acute pulmonary disease, central nervous system problems, severe renal disease, and severe nutritional compromise (unadjusted association only) were associated with higher likelihoods of death after discharge from the index surgical stay. Also, Veterans who waited longer to have their surgical amputation once admitted to the hospital or who were discharged to an extended care facility were more likely to die than those who received inpatient specialized rehabilitation services, as were Veterans who received inpatient consultative services. Dillingham and Pezzin found similar results in a study of elderly patients with dysvascular amputations [21]. In their study of a Medicare-based population, they noted that the $1 \mathrm{yr}$ mortality for elderly persons with major LLA was significantly less for those patients discharged to an inpatient rehabilitation program than those discharged to home or to a skilled nursing facility. Presumably, patients referred to rehabilitation are stable medically and achieve a higher level of functioning than those discharged to an extended care setting, which would account for some of this difference; however, Dillingham and Pezzin did not find significant differences between the characteristic of patients who received inpatient rehabilitation versus those who did not in terms of comorbid- 
JRRD, Volume 49, Number 10, 2012

Table 2.

Cox proportional hazard analysis.

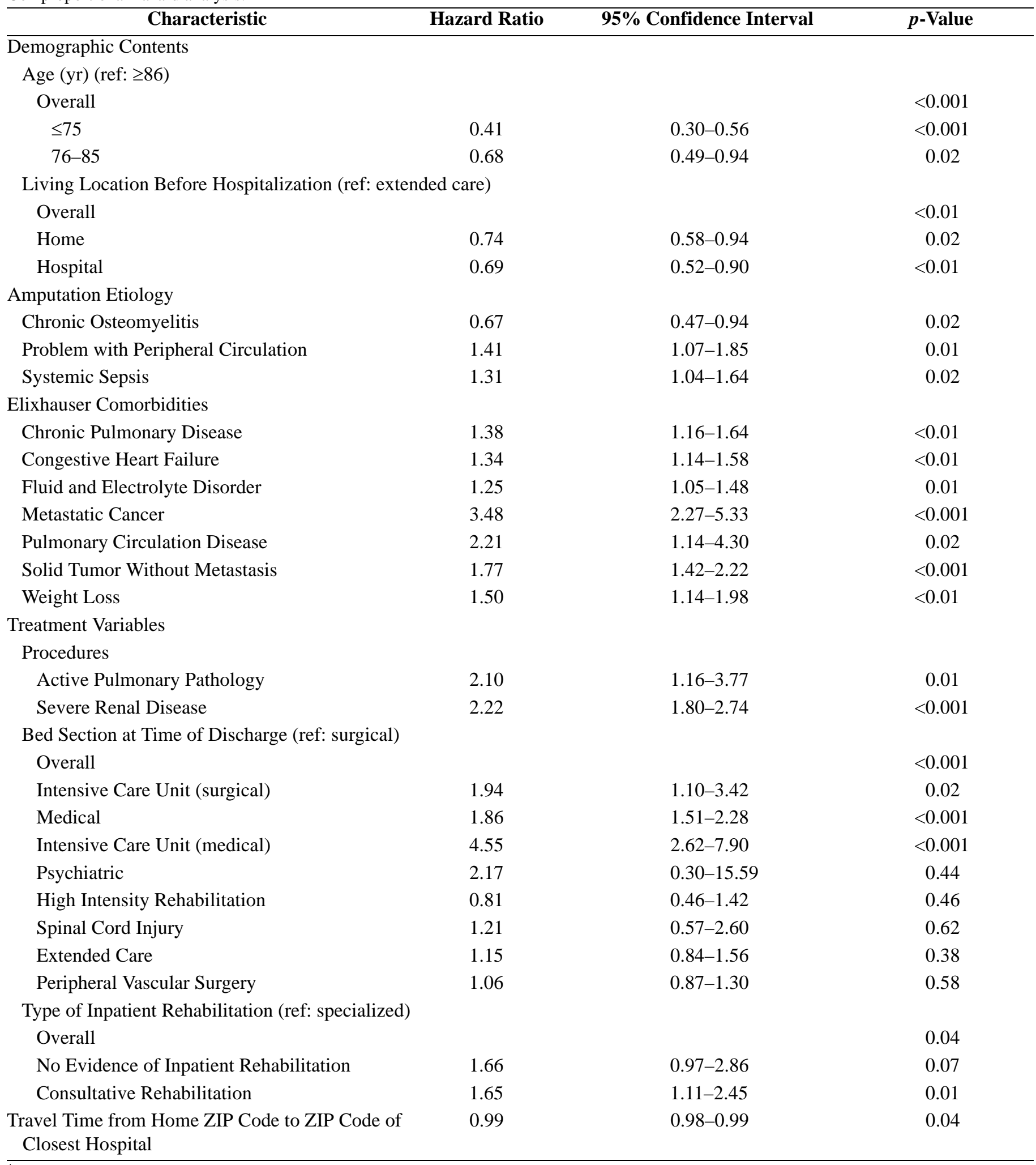

${ }^{*}$ Level of amputation, procedure for acute central nervous system, region, and wave were not listed in this table since they violated proportional hazards assumption. ref $=$ reference variable for comparison. 
Table 3.

Hazard ratios at different time points for variables violating proportional hazards assumption.

\begin{tabular}{|c|c|c|c|c|c|}
\hline \multirow{2}{*}{ Characteristic } & \multicolumn{5}{|c|}{ Hazard Ratio (95\% Confidence Interval) } \\
\hline & Od & $90 \mathrm{~d}$ & $180 \mathrm{~d}$ & $270 \mathrm{~d}$ & $365 \mathrm{~d}$ \\
\hline \multicolumn{6}{|c|}{ Level of Amputation (ref: unilateral transtibial) } \\
\hline Unilateral Transfemoral & $1.85(1.36-2.51)$ & $1.48(1.20-1.82)$ & $1.18(0.92-1.51)$ & $0.84(0.65-1.38)$ & $0.75(0.43-1.29)$ \\
\hline Bilateral Transtibial & $1.13(0.50-2.57)$ & $1.05(0.61-1.83)$ & $0.99(0.53-1.84)$ & $0.92(0.35-2.41)$ & $0.86(0.21-3.50)$ \\
\hline Bilateral Transfemoral & $2.16(1.38-3.39)$ & $1.65(1.11-2.47)$ & $1.26(0.83-1.92)$ & $0.96(0.59-1.58)$ & $0.73(0.39-1.34)$ \\
\hline $\begin{array}{l}\text { Acute Central Nervous System } \\
\text { Procedure }\end{array}$ & $2.23(1.60-3.11)$ & $1.55(1.22-1.98)$ & $1.08(0.73-1.58)$ & $0.75(0.41-1.38)$ & $0.51(0.21-1.22)$ \\
\hline \multicolumn{6}{|l|}{ Region (ref: Mountain Pacific) } \\
\hline Northeast & $1.56(1.05-2.33)$ & $1.14(0.86-1.51)$ & $0.83(0.56-1.25)$ & $0.61(0.32-1.15)$ & $0.44(0.17-1.10)$ \\
\hline Southeast & $1.04(0.72-1.49)$ & $1.13(0.89-1.45)$ & $1.24(0.92-1.67)$ & $1.35(0.85-2.17)$ & $1.49(0.75-2.95)$ \\
\hline Midwest & $0.58(0.38-0.89)$ & $0.75(0.57-1.00)$ & $0.97(0.70-1.34)$ & $1.25(0.75-2.07)$ & $1.63(0.78-3.41)$ \\
\hline South Central & $0.92(0.62-1.36)$ & $0.95(0.72-1.24)$ & $0.98(0.70-1.37)$ & $1.01(0.60-1.71)$ & $1.05(0.49-2.25)$ \\
\hline \multicolumn{6}{|l|}{ Wave (ref: year 1) } \\
\hline Year 2 & $0.94(0.67-1.32)$ & $0.65(0.48-0.88)$ & $0.45(0.32-0.62)$ & $0.31(0.20-0.47)$ & $0.21(0.12-0.36)$ \\
\hline
\end{tabular}

ities. The improved function achieved during the rehabilitation program may provide some level of protection from the deleterious effects of immobility.

Patients who underwent an amputation in year 2 were less likely to die after $90 \mathrm{~d}$ than patients who underwent an amputation in year 1 . Future studies will be essential to determine whether this is a data anomaly or represents improved outcomes.

\section{Environmental-Level Characteristics}

The environmental characteristic of travel time from the patient's home ZIP code to that of the nearest hospital was a variable not used in the original study. The VA has, for the past decade, been expanding primary care services into the local communities and more rural areas. The overarching goal of these community-based outpatient clinics is to reduce Veteran travel time to care. The VA also has the ability to purchase care in the community for eligible Veterans when necessary. We anticipated that patients with shorter travel times to a healthcare facility would have a lower mortality risk than those patients in ZIP codes remote from the nearest facility. Surprisingly, our results showed just the opposite. Although it seems counterintuitive that patients with shorter travel times from their home to a local hospital had a higher mortality rate than those who lived farther away, there are several possible explanations. The facility closest to the Veteran's home may not be the facility he or she actually uses for specialty care. Many Veterans live in rural areas, and while the local community hospital may be within the same ZIP code region as their home address, it may not offer the specialty services needed, requiring Veterans to travel long distances to receive specialty care at the VA facility. While the VA has community-based outpatient clinics offering primary care in more rural areas, specialty care is only provided at main VA facilities. The perception of access as noted by the proximity of a healthcare facility within the same or nearby ZIP code may not translate into true access, particularly for specialty care. Access to non-VA community services for specialty care at VA expense is regulated by strict criteria, and if a Veteran has no other source of healthcare insurance than VA, he or she may postpone services because of travel or cost barriers, presenting to the VA parent facility only when very ill. Veterans who live a long distance from a VA facility and lack a local community hospital to rely on in an emergency may be more motivated to seek care early to better maintain their health overall. In highly urban areas, where the Veteran may be within the same or adjacent ZIP code, there may be other nonspatial barriers to healthcare access. There may be a higher percentage of low socioeconomic Veterans with significant medical burden in urban areas.

There are several limitations to this study. The study was limited to the Veteran population, which is predominantly male. Race was not included because of the large amount of missing information.

The relationship between patients' locations and travel time to medical care services needs further examination. While travel time to appropriate care is certainly 
an important aspect to actual utilization of healthcare services, there are other environmental, nonspatial factors that may be as influential as travel time. In future analyses, we will seek to incorporate a number of these factors to better understand the relationship between the veteran's environment and access to care. Census data on the population in poverty, median income, or femaleheaded households can provide an indication of the socioeconomic profile of a Veteran's community. Linguistic barriers and service awareness can be captured using publicly available census data on the proportion of nonwhite minorities and education levels (i.e., proportion without a high school diploma). Transportation barriers can potentially be captured by investigating the number of households in the Veteran's community without a motor vehicle because those individuals who rely solely on public transportation may be disadvantaged in their ability to get the care they need. These variables will be added to the "environmental" domain included in future predictive models.

\section{CONCLUSIONS}

Mortality risk following LLA is high, particularly for frail elderly patients and those with multiple comorbidities, and the perception of access to healthcare may not translate to better outcomes. Knowledge of the types of procedures received during hospitalization appears to add valuable prognostic information over and above diagnostic information; further work is needed exploring issues surrounding access of specific types of care, particularly for the elderly disabled patient.

\section{ACKNOWLEDGMENTS}

\author{
Author Contributions: \\ Study concept and design: B. E. Bates, M. G. Stineman, D. Cowper \\ Ripley, J. E. Kurichi, P. L. Kwong, D. Xie. \\ Acquisition of data: D. Cowper Ripley. \\ Analysis and interpretation of data: B. E. Bates, M. G. Stineman, \\ D. Cowper Ripley, J. E. Kurichi, P. L. Kwong, D. Xie. \\ Drafting of manuscript: B. E. Bates, M. G. Stineman, D. Cowper Ripley, \\ J. E. Kurichi, P. L. Kwong, D. Xie. \\ Critical revision of manuscript for important intellectual content: \\ B. E. Bates, M. G. Stineman, D. Cowper Ripley, J. E. Kurichi. \\ Statistical analysis: P. L. Kwong, D. Xie, J. E. Kurichi. \\ Obtained funding: M. G. Stineman, B. E. Bates, J. E. Kurichi.
}

Financial Disclosures: The authors have declared that no competing interests exist.

Funding/Support: This article was based on work supported by the National Institutes of Health (grant R01-HD-042588-05A2). It is also supported by resources and the use of facilities at the Samuel S. Stratton VAMC, Albany, New York; the North Florida/South Georgia Veterans Health System (NF/SG VHS), Gainesville, Florida; and the University of Pennsylvania, Philadelphia, Pennsylvania.

Institutional Review: This observational study was approved by the institutional review boards at the Samuel S. Stratton VAMC, Albany, New York; the NF/SG VHS, Gainesville, Florida; and the University of Pennsylvania, Philadelphia, Pennsylvania.

Disclaimer: The views and opinions expressed in this manuscript are those of the authors and do not necessarily represent the policy of the VA.

\section{REFERENCES}

1. Bates BE, Stineman MG, Reker DM, Kurichi JE, Kwong PL. Risk factors associated with mortality in veteran population following transtibial or transfemoral amputation. J Rehabil Res Dev. 2006;43(7):917-28. [PMID:17436177] http://dx.doi.org/10.1682/JRRD.2006.03.0030

2. Dillingham TR, Pezzin LE, Shore AD. Reamputation, mortality, and health care costs among persons with dysvascular lower-limb amputations. Arch Phys Med Rehabil. 2005;86(3):480-86. [PMID:15759232] http://dx.doi.org/10.1016/j.apmr.2004.06.072

3. Feinglass J, Pearce WH, Martin GJ, Gibbs J, Cowper D, Sorensen M, Henderson WG, Daley J, Khuri S. Postoperative and late survival outcomes after major amputation: findings from the Department of Veterans Affairs National Surgical Quality Improvement Program. Surgery. 2001; 130(1):21-29. [PMID:11436008] http://dx.doi.org/10.1067/msy.2001.115359

4. Mayfield JA, Reiber GE, Maynard C, Czerniecki JM, Caps MT, Sangeorzan BJ. Survival following lower-limb amputation in a veteran population. J Rehabil Res Dev. 2001;38(3):341-45. [PMID:11440266]

5. Pohjolainen T, Alaranta H, Wikström J. Primary survival and prosthetic fitting of lower limb amputees. Prosthet Orthot Int. 1989;13(2):63-69. [PMID:2780262]

6. Remes L, Isoaho R, Vahlberg T, Hiekkanen H, Korhonen K, Viitanen M, Rautava P. Major lower extremity amputation in elderly patients with peripheral arterial disease: incidence and survival rates. Aging Clin Exp Res. 2008; 20(5):385-93. [PMID:19039278]

7. Tseng CL, Rajan M, Miller DR, Lafrance JP, Pogach L. Trends in initial lower extremity amputation rates among Veterans Health Administration health care System users from 2000 to 2004. Diabetes Care. 2011;34(5):1157-63.

[PMID:21411510]

http://dx.doi.org/10.2337/dc10-1775 
8. Kuo S, Fleming BB, Gittings NS, Han LF, Geiss LS, Engelgau MM, Roman SH. Trends in care practices and outcomes among Medicare beneficiaries with diabetes. Am J Prev Med. 2005;29(5):396-403. [PMID:16376702] http://dx.doi.org/10.1016/j.amepre.2005.08.010

9. Wang J, Imai K, Engelgau MM, Geiss LS, Wen C, Zhang P. Secular trends in diabetes-related preventable hospitalizations in the United States, 1998-2006. 2009;32(7):1213-17. [PMID: 19366966]

10. VIReC research user guide: Fiscal year 2000 VHA medical SAS inpatient datasets. Hines (IL): VHA Corporate Datasets Monograph; 2003.

11. Kubal JD, Webber S, Cooper DC, Waight S, Hynes DM. A primer on US mortality databases used in health services research. Vol. 5. Hines (IL): VA Information Resource Center; 2000.

12. VIReC research user guide: Fiscal year 2000 VHA medical SAS outpatient datasets. Hines (IL): VHA Corporate Datasets Monograph; 2003.

13. Corporate Databases Monograph VH. 2006 [cited 2007 Apr 18]; Available from:

http://www.virec.research.va.gov/References/links/ VHACorporateDatabaseMonograph2006Final.pdf

14. Bates BE, Kwong PL, Kurichi JE, Bidelspach DE, Reker DM, Maislin G, Xie D, Stineman M. Factors influencing decisions to admit patients to veterans affairs specialized rehabilitation units after lower-extremity amputation. Arch Phys Med Rehabil. 2009;90(12):2012-18. [PMID:19969162] http://dx.doi.org/10.1016/j.apmr.2009.07.016

15. Bates BE, Kurichi JE, Marshall CR, Reker D, Maislin G, Stineman MG. Does the presence of a specialized rehabilitation unit in a Veterans Affairs facility impact referral for rehabilitative care after a lower-extremity amputation? Arch Phys Med Rehabil. 2007;88(10):1249-55. [PMID:17908565] http://dx.doi.org/10.1016/j.apmr.2007.06.018

16. Kurichi JE, Kwong PL, Reker DM, Bates BE, Marshall CR, Stineman MG. Clinical factors associated with prescription of a prosthetic limb in elderly veterans. J Am
Geriatr Soc. 2007;55(6):900-6. [PMID:17537091]

http://dx.doi.org/10.1111/j.1532-5415.2007.01187.x

17. Kurichi JE, Stineman MG, Kwong PL, Bates BE, Reker DM. Assessing and using comorbidity measures in elderly veterans with lower extremity amputations. Gerontology. 2007;53(5):255-59. [PMID:17435390]

http://dx.doi.org/10.1159/000101703

18. Cox D. Regression models and life-tables. J R Stat Soc [Ser A]. 1972;34(2):187-220.

19. Aulivola B, Hile CN, Hamdan AD, Sheahan MG, Veraldi JR, Skillman JJ, Campbell DR, Scovell SD, LoGerfo FW, Pomposelli FB Jr. Major lower extremity amputation: outcome of a modern series. Arch Surg. 2004;139(4):395-99, discussion 399. [PMID:15078707]

http://dx.doi.org/10.1001/archsurg.139.4.395

20. O’Hare AM, Feinglass J, Reiber GE, Rodriguez RA, Daley J, Khuri S, Henderson WG, Johansen KL. Postoperative mortality after nontraumatic lower extremity amputation in patients with renal insufficiency. J Am Soc Nephrol. 2004;15(2):427-34. [PMID:14747390] http://dx.doi.org/10.1097/01.ASN.0000105992.18297.63

21. Dillingham TR, Pezzin LE. Rehabilitation setting and associated mortality and medical stability among persons with amputations. Arch Phys Med Rehabil. 2008;89(6):1038-45. [PMID:18503797] http://dx.doi.org/10.1016/j.apmr.2007.11.034

Submitted for publication February 16, 2012. Accepted in revised form April 17, 2012.

This article and any supplementary material should be cited as follows:

Bates BE, Xie D, Kurichi JE, Cowper Ripley D, Kwong PL, Stineman MG. Revisiting risks associated with mortality following initial transtibial or transfemoral amputation. J Rehabil Res Dev. 2012;49(10):1479-92.

http://dx.doi.org/10.1682/JRRD.2012.02.0030

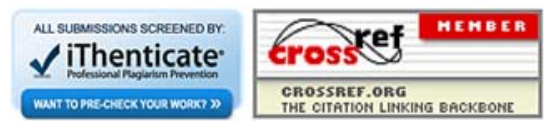


